\title{
Application of modern models of sustainable architecture in the use of natural light and effective utilization of energy in schools: a comparative study of Glasgow (Great Britain) and Isfahan (Iran)
}

\author{
M. Nilforoushan ${ }^{1}$, R. Hanna ${ }^{1} \&$ H. Sadeghi Naeini ${ }^{2}$ \\ ${ }^{1}$ The Glasgow School of Art, UK \\ ${ }^{2}$ School of Architecture Iran, University of Science \& Technology (IUST), \\ Iran
}

\begin{abstract}
This research examines day lighting levels and their impact on pupil's academic performance and health in primary schools. A significant volume of research literature was reviewed and analyzed. The main findings from this analysis were that there is a sketchy evidence to support the notion of daylight having an impact on performance and health. The research conducted a series of empirical studies in a number of primary schools both in Glasgow and Isfahan. The sample of schools chosen were representative of Glasgow city's population as two schools were selected from each part of the city (east, west, north, south and centre); a similar scenario was performed in Isfahan. The main finding, although tentative and slightly infirm, suggested that light levels did affect space utilization in classrooms and pupils seemed happier and more active in sunny classrooms than in shaded ones.
\end{abstract}

Keywords: daylight, energy, natural light, architecture, sustainable, design.

\section{Introduction}

Analysis of Iran's aims in achieving sustainable development in which energy utilization plays a significant role is of high priority. Thus accomplishing ways of reducing energy usage, particularly in buildings which use fossil fuels, is an 
important issue. Based on statistics, 38\% of Iran's energy is utilized in the construction section, out of which $70 \%$ is supplied by natural gas. Official statistics show that over the past 20 years, the amount of usage of fossil fuels in the construction section has multiplied by 4 to 5 times. The same illustrates that the value has increased by approximately 12 times its world value. So, due to this significant rise in energy consumption and to achieve the sustainable development of the country's aspirations, a rethinking of strategies in utilization of this type of fuel is essential. If this rethinking process does not take place, the country will become an importer of energy.

With respect to the effective role of the construction industry in reducing the waste of energy and considering the fact that Iran's climate has many sunny days and also taking into account Iran's traditional architecture in which light is highly accounted for as a separate element, numerous achievable, applicable and systematic results can be obtained. One of the main characteristics of natural light is its consecutiveness and variations during the period of a day. This plays an important role in psychological and physiological well-being. For instance, sunshine within a space can make one flourish and joyful, can affect occupants' moods and induce a feeling of dynamism and movement to a space through a change of quality (from sunrise to sunset) during different hours of a day. Consequently, an appropriate use and exploitation of both daylight and sunlight can result in more advantages to the building user in terms of heat and warmth, brightness and prevention of use of artificial light, which in turn will result in a reduction of energy usage.

More importantly, a reduction in energy usage can lead to a decrease in the formation of environmental toxic waste and green house gases such as carbon dioxide. This can be considered as an important step in the prevention of climate change and the earth heating up.

So, a sustainable architectural design demands a pattern that encompasses all values. This combination of environmental goals and the presentation of a suitable method to designers, construction practitioners and energy users will save a significant amount of energy. Actions include:

- Precise and proper understanding of environment and climate of the building to be constructed.

- Accurate consideration of the environment and the effective role of harmonization its relationship with the surrounding environment particularly in public buildings.

- Moving toward sustainability and robustness of the building and attention to effective life cycle of buildings.

- Appropriate use of local construction materials.

This paper attempts to present a number of practicable, comparable and localized solutions to maximize the reduction of energy usage, which can lead to an energy saving of 12 to $45 \%$ and a decrease in environmental pollution of approximately $25 \%$. 


\section{Significance of energy saving in schools}

Schools, as an important building typology, can play a significant role in saving energy in terms of fuel and electricity consumption. However, if there isn't any planned program for energy saving at schools, some negative impacts with regards to energy consumption will occur. About $22 \%$ of Iran's population, which is around 15 million students, are users of this type of buildings. Undoubtedly, the mentioned population shows the magnitude of the related problem. Consequently if some effective programs for energy saving were to be introduced to the design of school buildings, positive outcomes in terms of sustainability will be gained. Accordingly, school buildings' architecture, if it was based on day light and sunlight consideration and usage, has a prominent role to play in moving toward greater levels of sustainability.

\section{Daylight benefits}

Natural and daylight not only create a pleasing condition for vision, but also offers some health benefits such as Vitamin D and disinfections characteristics. Furthermore the reliance on this natural source of energy, which is environmentally friendly and renewable, helps reduce the consumption of fossil fuel and, in turn, greenhouse gases.

More usage of daylight in school buildings means a better environment, pleasurable spaces, a money saving strategy, more sustainability, a less energy consumption culture, and so on. However, there are some limitations and obstacles to achieving the above goals. Budgeting requirements, management problems, and the lack of awareness about energy saving are just a few examples.

\section{Sustainable architecture and energy}

Sustainability as a goal can make us design healthier buildings, robust urban environments and create better future under the umbrella of three main areas: environment, economics, and social justice. Surely, sustainability is known as a multidisciplinary approach, therefore architecture as well as other sciences and fields do play an important role in sustainability. Sustainable architecture for schools, that is energy efficient and maximises the use of natural light, will ultimately make buildings and environments healthier to occupy and better for pupils and teachers. Certainly, climate characteristics, sort of land use, relationship between buildings and geographical attributes, buildings' age, and some other similar matters are known as related factors in the design process of sustainable architecture. Undoubtedly, lessons on sustainability can be learnt from some ancient buildings and monuments if we were to critically examine them. There are some famous monuments in the historical city of Isfahan of which some are known as schools such as CHAHAR BAQ School, KHAJOO School, and also schools of SA'DY, HAFEZ. In these buildings, careful attention was played to the use of local and energy efficient materials, sustainable forms 
with an excellent capacity for climatic modification, and sensitive facades, all of which were considered to be vital design issues.

\subsection{The role of designers}

According to the importance of linkage between sustainability concepts and architectural design, the role of architects and interior designers may be redefined to creating some effective artefacts that are sustainable, healthy and energy efficient. There are several practical examples which show a shifting emphasis of architecture to the implementation of sustainable approaches to the design process of buildings.

In a school building with 3900 square meter floor area in Glasgow, Scotland, 23 roof windows were installed in 2009. This resulted in more than $90 \%$ of the indoor area gaining daylight, and as a consequence, about 51\% energy saving was achieved in terms of a decrease in using artificial lighting, Figure 1.

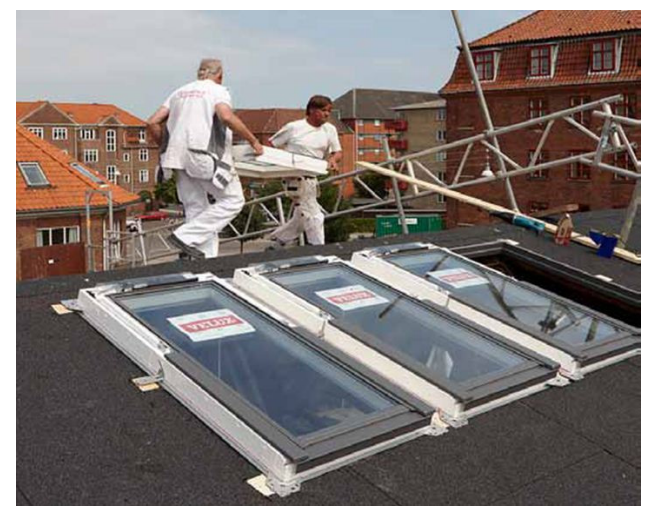

Figure 1: Roof windows installation in a school in Glasgow.

Another example of using day light is a school with 6700 square meter in USA-Washington in 1988. In this case about 40 roof windows were installed and this action's outcome was a reduction in building lighting cost of about $87 \%$ with reports of more daylight penetration and distribution.

According to UK reports, the average energy consumption in schools includes: $24 \%$ for lighting, $29 \%$ for heating systems, $10 \%$ for cooking, $8 \%$ for hot water, $29 \%$ for electric equipment.

\subsection{Material and method}

In this cross sectional study, two cities were selected, Glasgow in the UK and Isfahan in Iran. Data gathering from geographic centres in both cities, daylight assessment according to sun azimuth and altitude were also carried out.

In Isfahan city, there are 568 primary schools with a student population of 130,000 , which are scattered across five counties. These schools are divided into 
two categories: private $($ No. $=380)$, and governmental $($ No. $=188)$ schools. In comparison the number of primary schools in Glasgow is 149 with about 36,000 students

The research sample included a number of selected new schools from both cities which comprise $10 \%$ of new schools building stock. They have various designs, differ in location and were chosen from four geographical locations within each city (to represent heterogeneous conditions with respect to differences in temperature and other geographical factors). The questionnaire included 50 questions which were distributed to each school. These questions covered issues related to the impact of natural and artificial lights on health, well-being and performance, classroom layout in relation to windows and light penetration, the influence of light on student skills and abilities (writing, reading) and their behaviour. Also, daylight levels at different seasons are taken into account using duration tables to analyse the schools' lighting with respect to orientation of the classrooms (north, east, south, west), the floor of the building where classrooms are located, different months and times in the day. Light measuring instruments have been used to measure the quantity of the light, in Lux, in the classrooms and compare and analyze them. This enables the study to compare light conditions in two classrooms with opposite orientation at the same time.

\section{Results}

The study also addresses the behavioural role of teachers and students in managing the implementation of appropriate actions for energy conservation and usage, such as:

- Switching off the redundant lamps in the classroom during the day.

- Switching off the lamps immediately after the end of class.

- Controlling windows, i.e. whether they are open or closed to prevent the loss of energy.

- Continuous adjustment and monitoring of school's heating and cooling system.

- Students' appropriate use of warm water systems and adequate consumption.

- Maximum use of natural lighting- installing sufficient number of windows and skylights, and painting the walls with light colours to reduce artificial lighting needs during the day [1].

- Cleaning the lamps and replacing the ones with reduced lighting efficiency.

- Installing electronic sensors that automatically switch off electrical lights when spaces and classrooms are not in use.

- Paying attention to the heating impact of high wattage lamps in summer which may force a need for air conditioning in classrooms.

- Using the minimum necessary lighting in non-activity spaces such as inventories, parking, stairs, corridors, external spaces and toilets.

The research calculated that taking into account these measures will reduce the energy cost between 12 and $17 \%$. This change in the percentages relates directly to the year of construction and the number of students. Studies also show 
that larger schools and schools with 400 students compared to 200 student schools are more productive in terms of energy savings.

Programs running outside the schools working hours change the costs considerably. Because, these kinds of meeting or extra classes are mainly arranged in the evenings and afternoons, which significantly increases energy consumption and thus demands appropriate management and timetabling.

Student participation in this matter in schools could play an important role in consumption reduction and cost saving. Appropriate distribution of information and reform in norms and behaviours are very important. Actions that can make a difference include:

1. Improving the awareness of students and staff of the importance of energy conservation. All members of the school should participate in activities geared towards making energy saving an educational theme.

2. Using some students as candidates for energy monitoring in each class. They should be encouraged to take responsibility to control switching of lamps, the closing and opening of windows which will have implications for heating and cooling systems.

3. Encouraging and creating incentives for students to become successful promoting and managing energy reduction plans.

4. Rewarding successful schools with respect to factors, such as offering grants to improve building construction and maintenance, invest in low energy air conditioning systems and offering a low relative index of the number of students to space ratio.

5. Providing guidance to students on using appropriate scientific and practical methods, with respect to adopting psychological and sociological principles that can lead to an economic energy consumption style [2].

6. Encouraging voluntary saving which is a better approach in the view of experts. In this approach which is based on education and awareness, emphasis is placed on change in the mindset, increasing the incentives and motivating the people, enhancing the sensitivity of students to an optimum energy behaviour.

\section{Recommendations}

\subsection{Suggestions on user techniques}

1. Appropriate social education by schools, public media and newspapers can lead to a change of behaviour toward a more energy efficient attitude.

2. Educating students with related courses in science, that can improve their awareness of issues such energy efficiency, sustainability, green house gases and global warming.

3. Arranging new workshops for architects and other construction related staff, which teach good design practice on passive solar buildings and renewable energy generation [3]. 


\subsection{Suggestions about architecture techniques}

1. Appropriate use of standard and double (two layer) doors to reduce air draft and make school air tight.

2. Using double or triple glazed windows, which are energy efficient, since about $40 \%$ of energy loss of the buildings is from windows.

3. Controlling the classroom and other public environments in terms of providing necessary degree of warmth and using intelligent central heating systems equipped with measurement sensors of environmental temperature.

4. Isolating and standardizing of coolers canals.

5. Choosing sustainable construction materials, with respect to climate and the type of use in schools.

6. Making the adoption of article 19 of the building regulation compulsory for all current and future educational buildings.

7. Suggesting guidance for using appropriate construction material in buildings' exteriors with respect to climatic condition.

8. Making compulsory the use of entrance compartment with two doors to offset the loss of heat while one is open.

9. Designing external windows and the number of openings in relation to the degree of sun shine, direction and the number of sunny days in the specific locations. (Such analysis is underway in Isfahan which will be done in 8 levels and locations.)

10. Taking into account considerations such as, site analysis, the location, neighbourhood, heights and access.

\section{Conclusion}

If we compare Isfahan city in Iran with Glasgow in Scotland, it will be obvious that according to the geographic characteristic of Isfahan, a greater reliance on daylight in Isfahan might create more benefits than Glasgow. According to the sun's angles of azimuth and altitude in Isfahan, sunshine duration in Isfahan is about two times that of Glasgow.

Inspired by this fact, that sunlight in Glasgow is less than Isfahan, still aiming for an effective energy management system makes sense, and one way of doing this is maximizing the use of daylight in school buildings. Therefore, implementation of new techniques on maximizing daylight and improving energy efficiency in Isfahan school building architecture creates a sustainable condition. In this regard, a sustainable policy on urban planning and infrastructure management especially for school buildings should be considered. Public awareness of green house effects and the notion that the architecture of new school buildings should be designed according to daylighting and energy saving plans are parallel activities for achieving better conditions for society, environment and economics. 
58 Lighting in Engineering, Architecture and the Environment

\section{References}

[1] A guide for head teachers, governors, premises managers and school energy managers Saving energy in schools Visit the website at www.energyefficiency.gov.uk

[2] Formalised Peer Mentoring Pilot Evaluation, www.cypnow.co.ul

[3] Erin Belanger, Christine Kielb, Shao Lin, Asthma Hospitalization Rates Among Children, and School Building Conditions, by New York State School Districts, 1991-2001 